\title{
(6) OPEN ACCESS \\ Emergency Care Handover (ECHO study) across care boundaries: the need for joint decision making and consideration of psychosocial history
}

\author{
Mark A Sujan, ${ }^{1}$ Peter Chessum, ${ }^{2}$ Michelle Rudd, ${ }^{3}$ Laurence Fitton, ${ }^{4}$ \\ Matthew Inada-Kim, ${ }^{5}$ Peter Spurgeon, ${ }^{1}$ Matthew W Cooke ${ }^{1}$
}

\author{
Warwick Medical School, \\ University of Warwick, \\ Coventry, UK \\ ${ }^{2}$ Heart of England NHS \\ Foundation Trust, Birmingham, \\ UK \\ ${ }^{3}$ United Lincolnshire Hospitals \\ NHS Trust, Lincoln, \\ Lincolnshire, UK \\ ${ }^{4}$ Oxford Radcliffe Hospitals \\ NHS Trust, Oxford, UK \\ ${ }^{5}$ Hampshire Hospitals \\ NHS Foundation Trust, \\ Winchester, UK
}

\section{Correspondence to} Dr Mark A Sujan, Warwick Medical School, University of Warwick, Coventry CV4 7AL, UK; m-a.sujan@warwick.ac.uk

Received 25 June 2013 Revised 12 August 2013 Accepted 15 August 2013 Published Online First 11 September 2013

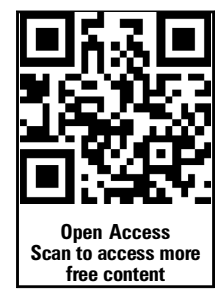

CrossMark

\section{To cite: Sujan MA} Chessum $P$, Rudd $M$, et al. Emerg Med J 2015;32 112-118.

\begin{abstract}
Background Inadequate handover in emergency care is a threat to patient safety. Handover across care boundaries poses particular problems due to different professional, organisational and cultural backgrounds. While there have been many suggestions for standardisation of handover content, relatively little is known about the verbal behaviours that shape handover conversations. This paper explores both what is communicated (content) and how this is communicated (verbal behaviours) during different types of handover conversations across care boundaries in emergency care. Methods Three types of interorganisational (ambulance service to emergency department (ED) in 'resuscitation' and 'majors' areas) and interdepartmental handover conversations (referrals to acute medicine) were audio recorded in three National Health Service EDs. Handover conversations were segmented into utterances. Frequency counts for content and language forms were derived for each type of handover using Discourse Analysis. Verbal behaviours were identified using Conversation Analysis.

Results 203 handover conversations were analysed. Handover conversations involving ambulance services were predominantly descriptive $(60 \%-65 \%$ of utterances), unidirectional and focused on patient presentation (75\%-80\%). Referrals entailed more collaborative talk focused on the decision to admit and immediate care needs. Across all types of handover, only $1.5 \%-5 \%$ of handover conversation content related to the patient's social and psychological needs.

Conclusions Handover may entail both descriptive talk aimed at information transfer and collaborative talk aimed at joint decision-making. Standardisation of handover needs to accommodate collaborative aspects and should incorporate communication of information relevant to the patient's social and psychological needs to establish appropriate care arrangements at the earliest opportunity.
\end{abstract}

\section{INTRODUCTION}

Inadequate handover practices are recognised as a threat to patient safety worldwide. ${ }^{1-3}$ A report issued by the Institute of Medicine in the USA suggests that ineffective handover has been identified as one of the leading causes of medical error in the emergency department (ED). ${ }^{4}$ Poor handover has been shown to contribute to treatment delays, ${ }^{5}$ repetition of assessments, ${ }^{6}$ medication errors, ${ }^{7}$ avoidable readmissions and increased costs. ${ }^{8}$ Factors that may affect the quality of handover include unclear structure of the handover conversation; ${ }^{9}$ frequent distractions; ${ }^{10}$ inadequate documentation ${ }^{11}$ and overreliance on documentation; ${ }^{12}$ and a lack of training in handover and non-technical skills. ${ }^{13}$

Studies of handover in the ED have often investigated transfer of information or responsibilities between shifts, where handover typically takes place between individuals from the same discipline. ${ }^{14}{ }^{15}$ Efforts aimed at improving handover have predominantly focused on standardisation of the transfer of information from sender to receiver, for example, through the introduction of structured communication protocols, such as Situation-BackgroundAssessment-Recommendation (SBAR). ${ }^{16}{ }^{17}$ Much less is known about handover across care boundaries. Interdepartmental and interorganisational handover requires more negotiation and coordination than shift handover due to different contextual circumstances, such as different professional backgrounds and terminology, unequal distribution of power between departments and organisations, lack of established working relationships, less face-to-face contact and less awareness of the other department's or organisation's current state. ${ }^{18}$ All communicative acts have a content dimension and a relational dimension, which defines and reinforces the relationship between the parties. ${ }^{19}$ There is little empirical evidence available that describes the collaborative aspects of handover conversations and how these are shaped by the interaction and by the verbal and non-verbal behaviours of individuals. $^{20}$

This paper explores both what is communicated (content) and how this is communicated (verbal behaviours) during different types of handover conversations across care boundaries in emergency care. This provides a basis for understanding and improving handover across interdepartmental and interorganisational care boundaries.

\section{METHODS}

\section{Setting}

Organisations participating in this study were two English National Health Service (NHS) ambulance services and three English NHS hospitals (ED and acute medical ward or clinical decision unit). Each ambulance service provided emergency care in the catchment area of one study hospital. The ambulance service providing transportation to the third study hospital felt unable to participate in this study. As a result, no data involving ambulance service staff were collected in the third pathway.

Hospital A is part of a large NHS Foundation Trust and provides services to a deprived city community with ethnic diversity. Hospital B is part of 
Table 1 Basic characteristics of participating hospitals

\begin{tabular}{lllll}
\hline & Population & Beds & Annual ED attendances & ED bays \\
\hline Hospital A & 440000 & 750 & 110000 & 30 \\
Hospital B & 650000 & 850 & 90000 & 36 \\
Hospital C & 300000 & 400 & 49000 & 22 \\
\hline \multicolumn{7}{l}{ ED, emergency department. }
\end{tabular}

an NHS Trust consisting of four hospitals. The population served is slightly younger than the national average, and it has above-average health and life expectancy. Hospital $\mathrm{C}$ is a District General Hospital providing services to an ethnically diverse and rural population.

Table 1 provides an overview of general characteristics of the three hospitals.

\section{Research ethics}

The study had NHS research ethics approval from South Birmingham Research Ethics Committee (reference 11/WM/ 0087), as well as institutional approval at all participating organisations.

\section{Data collection}

Three different types of interorganisational and interdepartmental handovers were selected for this study: handover from ambulance service to ED staff in 'resuscitation' (paramedic to senior ED doctor or resuscitation team), handover from ambulance service to ED staff in the 'majors' area (paramedic to senior ED nurse) and telephone referrals from ED to acute medicine (different grades of ED doctors to different grades of acute medicine doctors or senior nurses). The two ambulance services had implemented the Age-Time-Mechanisms-Injury-Signs-Treatments (ATMIST) handover tool for handover of trauma patients.

Patient handovers were audio recorded by members of the project team during the day and evening (8:00-22:00) for a period from November 2011 to July 2012 on days when the researchers were on the respective site. Participants had been informed of the study via a participant information leaflet and had been asked to provide written consent before the start of the data collection period. The researchers recorded handover from the ambulance services using a small voice recorder. Referrals by telephone were recorded by asking the referring party to use a small combined earphone and microphone, which enables recording of telephone conversations. Audio recordings were subsequently transcribed and all identifiers removed.

\section{Data analysis}

Transcripts of handover conversations were segmented into utterances and analysed using Discourse Analysis. ${ }^{21}$ In a first step, utterances were coded for their content and their language form using a coding scheme adopted from a study investigating the quality of handover between ED doctors and hospital doctors in the USA. ${ }^{20}$ The project team discussed the appropriateness of the coding scheme in a review meeting. It was felt that the category 'history' was broad and may hide important issues, such as the social situation and psychological needs of patients. As a result, this category was split into two separate categories: 'clinical history' and 'social history'. All other categories were adopted without change. The coding scheme is described in table 2 .
Two of the authors (MAS and PC) coded an initial random sample of 30 transcripts of audio recordings collaboratively in order to allow familiarisation with the coding scheme. Ambiguities and uncertainties were resolved in discussion. One researcher (PC) subsequently coded the remaining audio recordings independently. Simple frequency counts of handover content and language form were performed for each type of handover and for each study site.

During the second phase of the analysis, the broader view of Conversation Analysis was adopted. ${ }^{22}$ Utterances were interpreted as taking turns at talk, which is both facilitated and dependent on the behaviour and the utterances of the other participant. The researchers identified sequences of turn taking that exhibited recurring patterns.

\section{RESULTS}

In total, 203 recordings of handover conversations were included in the analysis. Another 67 recordings were excluded due to excessive background noise, poor recording quality or technical failures of the recording equipment (eg, problems with the microphone for recording telephone conversations). Table 3 shows the number of recordings for each site and type of handover, the respective median age of the patients and the mean duration for the different types of handover at each site.

\section{Content}

Table 4 provides an overview of the frequency with which particular content was communicated during each type of handover. Approximately $78 \%-80 \%$ of handover conversation content for resuscitation patients, and $74 \%$ of handover conversation content for 'majors' patients was concerned with the patient's previous and current status (category 'patient presentation'). Approximately 4\%-5\% of utterances were concerned with aspects of the patient's future care (category 'assessment'), and $11 \%-15 \%$ of utterances served to establish a friendly and professional relationship. In general, referrals were more forward looking: 53\%-67\% of utterances were concerned with the patient's previous and current status, 15\%-19\% with aspects of future care and 16\%-18\% with establishing a friendly and professional relationship.

\section{Language forms and patterns of interaction}

Across the sites, resuscitation handovers lasted between $38 \mathrm{~s}$ and $4 \mathrm{~min}$, handovers for patients in the 'majors' area lasted between $30 \mathrm{~s}$ and $6 \mathrm{~min}$ and referrals to acute medicine lasted between $1 \mathrm{~min}$ and approximately $7 \mathrm{~min}$. Frequency counts for the language forms used are shown in table 5. Handovers from ambulance crews were predominantly descriptive $(61 \%-66 \%$ of utterances) and unidirectional. Following the descriptive information provided by the ambulance crew were often a number of specific questions by the recipient. In resuscitation, there were frequently several questions (12\%-14\% of utterances) intended to elicit additional clinical information relevant to the patient's immediate treatment. In 'majors', there were often one or two questions $(5 \%-6 \%)$ intended to elicit information on topics that were mandatory to document, such as pain and allergy status.

In comparison, referrals contained a slightly smaller proportion of descriptive utterances $(45 \%-50 \%)$ and slightly more frequently open and closed questions (14\%-16\%). A recurring type of interaction consisted of the provision of patient demographics and details of the patient's current status by the referring party. The conversation then shifted to the joint identification for the reason to admit. This was followed by a discussion about actions that should be taken immediately. The 
Table 2 Coding scheme (adapted from ref. ${ }^{20}$ )

\begin{tabular}{|c|c|}
\hline Coding category & Definition \\
\hline \multicolumn{2}{|l|}{ Content } \\
\hline \multicolumn{2}{|l|}{ Patient presentation } \\
\hline Patient identifiers & Statements that convey patient identifiers such as name, date of birth or hospital number. \\
\hline Clinical history & The patient's past medical problems/conditions that are pertinent to the current diagnosis or clinical impression. \\
\hline Social history & $\begin{array}{l}\text { The patient's social circumstances and psychological needs describing, for example, housing situation and existing care arrangements, family } \\
\text { or friends accompanying, etc. }\end{array}$ \\
\hline Symptom & Descriptions and explanations that provide information about symptoms of concern. \\
\hline Procedure & $\begin{array}{l}\text { Statements about pertinent laboratory data, pertinent test results, medications and evaluation that already been performed to address the } \\
\text { patient's current condition. }\end{array}$ \\
\hline \multicolumn{2}{|l|}{ Assessment } \\
\hline Treatment & Statements about future medical procedures to be taken to address the patient's current problem. \\
\hline Clinical impression & Identification of the current clinical impression, naming the problem or reasons for the problem. \\
\hline Prognosis & Probabilistic statement about patient's future condition based on completed or proposed treatments. \\
\hline Outcome & Definite utterances about the result of the handover, for example, accept, not accept, wait and see. \\
\hline Transfer of responsibility & Statements about what was being asked of the recipient of the handover. \\
\hline \multicolumn{2}{|l|}{ Professional environment } \\
\hline Logistic processes & Descriptive or evaluative talk about logistics or procedural issues in emergency department, hospital, or healthcare system. \\
\hline Courtesies & Statements such as thank you, greeting and closing remarks, etc., that provide a context of professional courtesy. \\
\hline \multicolumn{2}{|l|}{ Language form } \\
\hline \multicolumn{2}{|l|}{ Information seeking } \\
\hline Closed question & An utterance that is designed to solicit specific information. \\
\hline Open question & An utterance that is designed to solicit information in a manner that affords the respondent the opportunity to elaborate. \\
\hline Clarifying question/request & An utterance that is a question designed to seek clarification of another's immediately preceding utterance. May take the form of a request. \\
\hline \multicolumn{2}{|l|}{ Information giving } \\
\hline Description & Utterances that provide description about the patient and the patient's past or present condition and circumstances. \\
\hline Explanation & Utterances that state the facts and make an inference about the patient. \\
\hline Rationale & $\begin{array}{l}\text { A justification is offered to account for any medical procedures, tests, medications or recommendations concerning the patient. The intent is } \\
\text { to justify why an action has been taken or will be taken in the future. }\end{array}$ \\
\hline Directive & Advisements, orders or recommendations that inform patient evaluation, treatment and disposition. \\
\hline Context talk & Talk about contextual issues in clinical environment such as logistics and procedures. \\
\hline Social amenities & Utterances in which physicians exchange courtesies and talk that tells the sender that the receiver is paying attention. \\
\hline Decision & Utterances in which the physician accepts or does not accept the patient. May be directly stated or implied. \\
\hline \multicolumn{2}{|l|}{ Information verifying } \\
\hline Read-back & Statements that paraphrase or restate what the other has said. \\
\hline
\end{tabular}

receiving party led these two phases of the conversation through questions and directives. The receiving party often tried to summarise explicitly the reason to admit. The conversation closed with a short phase about the patient's location or logistical details.

Table 6 shows part of a referral transcript exhibiting a typical pattern. The ED doctor (sender) provides a short descriptive monologue outlining the patient's current status (rows 1-7). The receiving acute medicine doctor (receiver) then takes the lead in the conversation and strongly guides the ED doctor (sender) in articulating the reason for admission (rows 16-25). The receiving doctor then attempts to summarise this and seeks confirmation (rows 26-27).

\section{Communication of social circumstances and psychological needs}

The median age of patients across sites and handover types ranged from 60 to 75 years, suggesting that a high proportion of patients in the ED were elderly. However, only approximately $2 \%-5 \%$ of ambulance service handover communication content

Table 3 Number of audio recordings, median age of patients and median duration of handover across sites

\begin{tabular}{|c|c|c|c|c|c|c|c|c|c|}
\hline & \multicolumn{3}{|c|}{ Number of audio recordings } & \multicolumn{3}{|c|}{ Median age of patients } & \multicolumn{3}{|c|}{$\begin{array}{l}\text { Median duration of handover in minutes } \\
\text { (low-high; IQR) }\end{array}$} \\
\hline & Resuscitation & Majors & Referrals & Resuscitation & Majors & Referrals & Resuscitation & Majors & Referrals \\
\hline Ambulance A/Hospital A & 14 & 40 & 31 & 75 & 60 & 70 & $\begin{array}{l}1: 36 \\
(0: 58-2: 19 ; \text { IQR } 0: 30)\end{array}$ & $\begin{array}{l}1: 14 \\
(0: 30-6: 01 ; \text { IQR 1:10) }\end{array}$ & $\begin{array}{l}2: 29 \\
(1: 02-5: 08 ; \text { IQR 0:52) }\end{array}$ \\
\hline Ambulance B/Hospital B & 20 & 39 & 26 & 69 & 73 & 73 & $\begin{array}{l}2: 10 \\
(0: 38-4: 00 ; \text { IQR 1:33) }\end{array}$ & $\begin{array}{l}2: 08 \\
(1: 02-4: 35 ; \text { IQR 1:03) }\end{array}$ & $\begin{array}{l}3: 27 \\
(1: 35-6: 50 ; \text { IQR 2:13) }\end{array}$ \\
\hline Hospital C & $\mathrm{n} / \mathrm{a}$ & $\mathrm{n} / \mathrm{a}$ & 33 & $\mathrm{n} / \mathrm{a}$ & $\mathrm{n} / \mathrm{a}$ & 70 & $\mathrm{n} / \mathrm{a}$ & $\mathrm{n} / \mathrm{a}$ & $\begin{array}{l}2: 22 \\
(1: 15-6: 03 ; \text { IQR 1:54) }\end{array}$ \\
\hline
\end{tabular}


Table 4 Frequency of handover communication content

\begin{tabular}{|c|c|c|c|c|c|c|c|}
\hline & \multicolumn{7}{|c|}{ Percentage of utterances for each handover type and study site (total number) } \\
\hline & \multicolumn{2}{|c|}{ Resuscitation } & \multicolumn{2}{|l|}{ Majors } & \multicolumn{3}{|l|}{ Referral } \\
\hline & A & B & A & B & A & B & C \\
\hline \multicolumn{8}{|l|}{ Patient presentation } \\
\hline Patient identifiers & $5.5(14)$ & $1.9(12)$ & $4.7(45)$ & $5.0(69)$ & $8.9(155)$ & $8.8(124)$ & 13.6 (178) \\
\hline Clinical history & $46.2(117)$ & $25.5(164)$ & $37.1(354)$ & $42.0(574)$ & $18.5(322)$ & $16.7(234)$ & $25.3(330)$ \\
\hline Social history & $3.2(8)$ & $2.5(16)$ & $3.5(33)$ & $5.4(74)$ & $2.8(49)$ & $1.4(20)$ & $2.5(33)$ \\
\hline Symptom & $10.3(26)$ & $16.1(104)$ & $14.1(134)$ & $10.6(145)$ & $9.5(166)$ & $11.5(161)$ & $4.0(52)$ \\
\hline Procedure & $15.0(38)$ & $32.3(208)$ & $14.9(142)$ & $11.5(157)$ & 19.9 (347) & $14.8(208)$ & $21.7(283)$ \\
\hline \multicolumn{8}{|l|}{ Assessment } \\
\hline Treatment & $0(0)$ & $5.0(32)$ & $1.7(16)$ & $0.3(4)$ & $8.1(142)$ & $10.0(140)$ & $4.0(52)$ \\
\hline Clinical impression & $4.3(11)$ & $0(0)$ & $6.5(62)$ & $0.7(9)$ & $3.2(55)$ & $5.6(78)$ & $6.5(85)$ \\
\hline Prognosis & $0(0)$ & $0(0)$ & $0(0)$ & $0(0)$ & $1.8(33)$ & $1.9(26)$ & $0.3(4)$ \\
\hline Outcome & $0(0)$ & $0(0)$ & $0(0)$ & $3.1(42)$ & $2.1(37)$ & $2.6(36)$ & $2.0(26)$ \\
\hline Transfer of responsibility & $0(0)$ & $0(0)$ & $0(0)$ & $0.1(1)$ & $4.6(80)$ & $5.6(78)$ & $2.5(33)$ \\
\hline \multicolumn{8}{|l|}{ Professional environment } \\
\hline Logistic processes & $4.3(11)$ & $5.6(36)$ & $2.9(28)$ & $5.9(81)$ & $4.6(80)$ & $3.3(46)$ & $1.0(13)$ \\
\hline Courtesies & $11.1(28)$ & $11.2(72)$ & $14.8(141)$ & $15.4(211)$ & 16.0 (279) & 18.1 (254) & 16.6 (217) \\
\hline
\end{tabular}

and only $1.5 \%-2.8 \%$ of handover content of referrals related to the social circumstances and psychological needs of the patient, which may be particularly relevant for elderly patients. The analysis identified three recurring triggers that led to the discussion of social and psychological aspects: (i) the ambulance service was alerted by the patient's carer or family member, (ii) the patient's current episode was related to their social circumstances and (iii) during referral there was no clear reason provided to admit an elderly patient. The presence of the first two triggers could act as prompts for the sender to provide a brief description, while the latter trigger could prompt the receiver to query the sender for information through the use of questions. Table 7 provides examples for each of these triggers from the transcripts of referrals.

\section{DISCUSSION}

The results suggest that in terms of content the different handover conversation types focused predominantly on physiological priorities of the patient. The patient's social circumstances and psychological needs were discussed less frequently, and such discussion was initiated by a small number of triggers. The results further suggest that handover conversations may entail both unidirectional transfer of information and collaborative elements aimed at joint decision-making. During the collaborative phases, leadership of the conversation often shifts from sender to receiver. The standardisation of handover practices should aim to provide a structure able to accommodate these collaborative aspects, and it should incorporate the communication of information relevant to the patient's social and psychological needs to establish appropriate care arrangements at the earliest opportunity.

In the present study, at least half of the patient sample were aged 60 years and above. A recently published best-practice guideline (the Silver Book) within the NHS describes the urgent care needs of older people and sets out the competencies that are required to meet their needs effectively. ${ }^{23}$ A commentary to

Table 5 Frequency of language forms

\begin{tabular}{|c|c|c|c|c|c|c|c|}
\hline & \multicolumn{7}{|c|}{ Percentage of utterances for each handover type and study site (total number) } \\
\hline & \multicolumn{2}{|c|}{ Resuscitation } & \multicolumn{2}{|l|}{ Majors } & \multicolumn{3}{|l|}{ Referral } \\
\hline & A & B & A & B & A & B & C \\
\hline \multicolumn{8}{|l|}{ Information seeking } \\
\hline Closed question & $3.5(9)$ & $11.2(72)$ & $4.8(46)$ & $5.0(68)$ & $8.9(155)$ & $11.1(156)$ & $11.6(151)$ \\
\hline Open question & $10.9(28)$ & $1.2(8)$ & $0.9(9)$ & $1.0(14)$ & $5.3(93)$ & $5.1(72)$ & $4.5(59)$ \\
\hline Clarifying question & $2.7(7)$ & $3.7(24)$ & $2.5(24)$ & $3.8(52)$ & $1.8(31)$ & $3.3(46)$ & $4.5(59)$ \\
\hline \multicolumn{8}{|l|}{ Information giving } \\
\hline Description & $61.3(157)$ & $62.7(404)$ & $66.0(630)$ & $65.8(900)$ & $48.2(840)$ & $50.8(714)$ & $45.6(596)$ \\
\hline Explanation & $5.5(14)$ & $0.6(4)$ & $1.3(12)$ & $0.7(10)$ & $4.9(86)$ & $2.2(31)$ & $4.6(60)$ \\
\hline Rationale & $3.5(9)$ & $1.9(12)$ & $6.1(58)$ & $0.4(5)$ & $2.1(37)$ & $3.3(46)$ & $2.5(32)$ \\
\hline Directive & $0.4(1)$ & $5.6(36)$ & $2.3(22)$ & $2.3(31)$ & $0.3(6)$ & $1.1(15)$ & $1.6(21)$ \\
\hline Context talk & $0.8(2)$ & $1.2(8)$ & $1.5(14)$ & $5.4(74)$ & $5.3(93)$ & $1.4(20)$ & $2.5(33)$ \\
\hline Social amenities & $11.3(29)$ & $10.6(68)$ & $14.7(140)$ & $15.2(208)$ & $16.0(279)$ & $18.1(254)$ & $16.6(217)$ \\
\hline Decision & $0(0)$ & $0(0)$ & $0(0)$ & $0.1(2)$ & $2.1(37)$ & $2.2(31)$ & $2.0(26)$ \\
\hline \multicolumn{8}{|l|}{ Information verifying } \\
\hline Read-back & $0(0)$ & $1.2(8)$ & $0(0)$ & $0.2(3)$ & $4.9(86)$ & $1.4(20)$ & $4.0(52)$ \\
\hline
\end{tabular}


Table 6 Excerpt of referral transcript-receiving party guides conversation on decision to admit

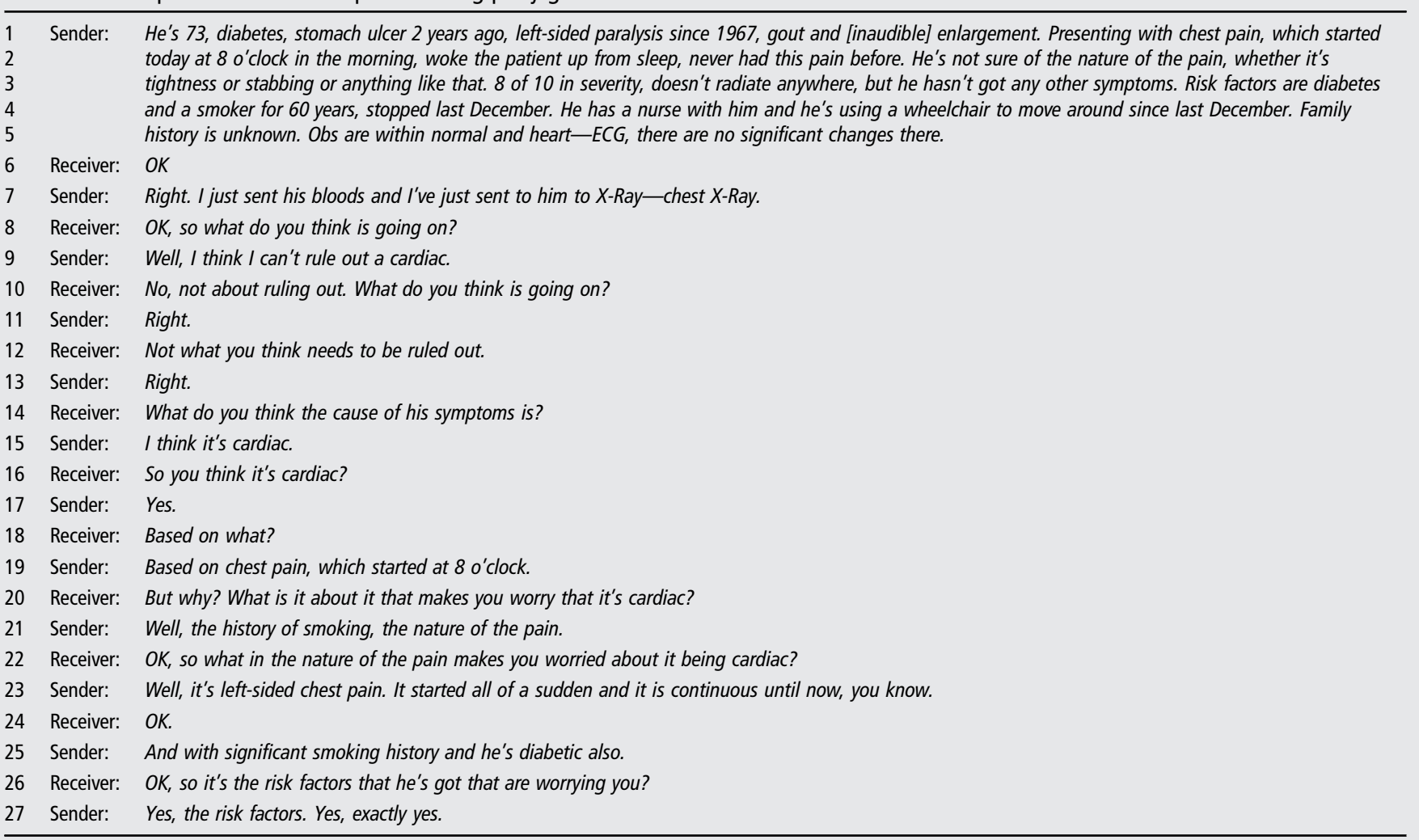

Table 7 Examples of triggers that may prompt discussion of social and psychological issues

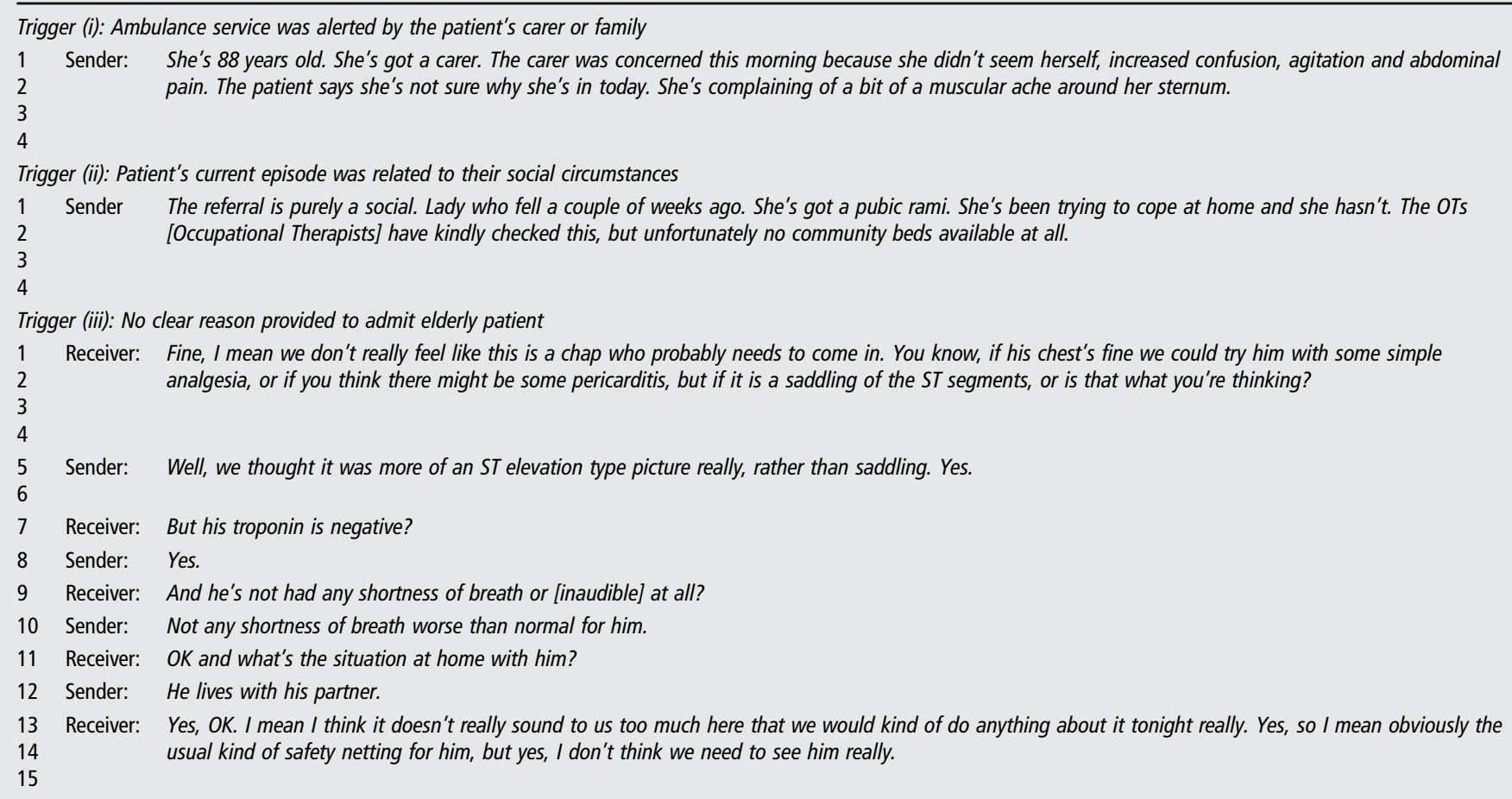

the guideline calls for multidisciplinary assessments that take place at the earliest possible opportunity in order to deliver coordinated care. ${ }^{24}$ The findings of the present study suggest that only a very small proportion of the handover conversation is dedicated to the discussion of the patient's social circumstances and psychological needs. These are usually discussed in cases where the patient's relatives or carers alerted the ambulance service, where the patient's current episode was in direct 
relation to their social circumstances or where there was no clear reason for admission of an elderly patient. While it could be argued that in a busy ED environment, the elicitation and assessment of comprehensive social information should be left to inpatient speciality teams who may have more time to ascertain and determine the significance of these factors, such a practice also bears risks to patient safety. Ambulance crews, who have seen the patient's home environment, are often best placed to provide important initial background information to the ED. The majority of patients will not be admitted to hospital, but will be discharged from the ED, and early consideration of the social history and psychological needs of the patient may facilitate the discharge planning process and contribute to reducing delays and unnecessary reattendances. The study raises questions about the extent to which early consideration of psychosocial aspects is currently supported by the handover process in the participating study sites.

Handover is often regarded as the transfer of information from sender to a more or less passive receiver. ${ }^{19}{ }^{25}$ This is sometimes described using analogies to sports such as 'passing the baton' or something similar. As a result, the most frequently encountered recommendation for improving handover communication is that of standardisation through procedures, checklists or mnemonics and appropriate training in their use. ${ }^{10}{ }^{17}$ In the UK, trauma guidelines now often include the use of the ATMIST handover tool for handover of trauma patients in resuscitation. Even though this logically feels like it should reduce the instances of critical information being omitted, there is no reliable body of evidence to suggest that standardisation of handover provided sustainable improvements in patient outcomes. $^{2}{ }^{16}$ Patterson and Wears ${ }^{19}$ point out that there are different complementary framings through which the purpose of handover can be viewed. They caution that the narrow focus of handover improvement efforts on the information-transfer framing may be impoverishing and limiting. The results of the present study support this view. The above analysis indicates that handover conversations may entail both unidirectional descriptive phases and collaborative phases during which the parties involved aim to reach a shared understanding of the patient's situation and needs, and try to make a joint decision about the best way to proceed. During these phases, the leadership of the conversation may shift, and far from being passive, the receiver may take charge of the conversation through guiding questions and prompts, and explicit summaries of their understanding. Different types of handovers exhibit these dynamic characteristics to a different extent. The predominantly unidirectional and descriptive structure of ambulance service handover may lend itself more readily to standardisation based on the information-transfer model, even though it could be argued that these types of handovers should be less unidirectional with more read-back and active information seeking from the receiving party. More importantly, though, standardisation of handovers, such as referrals, which entail a significant amount of collaborative talk, may require a different approach able to accommodate changes in leadership and joint decision-making. Anecdotally, referrals are often described as difficult conversations by ED clinicians. This may be due to the preconception of handover as a unidirectional activity, which may lead to frustration when the conversation changes leadership and enters the collaborative phases. Standardisation of and training in handover should aim to make explicit the need for collaborative aspects of handover conversations in order to ensure that staff possess awareness of and appropriate skills to engage in these collaborative aspects of handover. Adopting such a dynamic model of handover conversations may contribute to making these more effective and reducing the negative personal feelings resulting from unexpected discussions.

\section{LIMITATIONS}

The process of audio recording conversations may have introduced an element of reactivity as participants were aware that their conversations were being recorded. As a result, participants may have behaved in ways that they felt were appropriate or particularly desirable. The researchers tried to mitigate this effect by explaining to participants that the data collection was for research purposes only and that all data would be anonymised.

The study focused on the description of the dynamic structure of handover conversations. The data collection did not consider the accuracy of the information transmitted or whether this was received appropriately. No information on patient outcomes was collected, and hence, it was not possible to determine the actual effect on patient care of the handovers recorded.

The study did not consider conversations that may have taken place after the handover or whether written documentation was consulted subsequently. This means that low-frequency counts of handover content do not imply that this information was not in other ways transmitted to the receiving party. However, lowfrequency counts indicate that certain topics are not routinely communicated during handover, and often this may be the only opportunity participants have for a formal verbal exchange of information.

\section{CONCLUSION}

A narrow focus on handover as an information-transfer activity may limit the options for improvement, and complementary perspectives should be considered. Handover may entail both descriptive talk aimed at information transfer and collaborative talk aimed at joint decision-making. Standardisation of handover needs to accommodate collaborative aspects and should incorporate communication of information relevant to the patient's social and psychological needs to establish appropriate care arrangements at the earliest opportunity.

Acknowledgements We are grateful to staff from the five participating NHS organisations. Dr Stephen Cross was part of the project team. Simon Horniblow and Sally Beer assisted with data collection. Professor Matthew Costa provided helpful comments on drafts of the paper. Bianca Diete provided insightful discussions about social care arrangements and requirements.

Contributors MAS, MWC, PS and MI-K designed the study. MAS was chief investigator, led the data analysis and drafted the manuscript. MR and PC collected the data and contributed to the data analysis. All authors contributed to the interpretation of findings and to the writing and review of the manuscript.

Funding This project was funded by the National Institute for Health Research Health Services and Delivery Research (NIHR HS\&DR) programme (project number 10/1007/26). Visit the HS\&DR website for more information. The views and opinions expressed therein are those of the authors and do not necessarily reflect those of the HS\&DR programme, NIHR, NHS or the Department of Health.

\section{Competing interests None.}

Ethics approval South Birmingham Research Ethics Committee.

Provenance and peer review Not commissioned; externally peer reviewed.

Open Access This is an Open Access article distributed in accordance with the Creative Commons Attribution Non Commercial (CC BY-NC 3.0) license, which permits others to distribute, remix, adapt, build upon this work non-commercially, and license their derivative works on different terms, provided the original work is properly cited and the use is non-commercial. See: http://creativecommons.org/ licenses/by-nc/3.0/ 


\section{REFERENCES}

1 Bost $N$, Crilly J, Wallis $M$, et al. Clinical handover of patients arriving by ambulance to the emergency department-a literature review. Int Emerg Nurs 2010;18:210-20

2 Cohen MD, Hilligoss PB. The published literature on handoffs in hospitals: deficiencies identified in an extensive review. Qual Saf Health Care 2010;19:493-7.

3 Raduma-Tomas MA, Flin R, Yule $S$, et al. Doctors' handovers in hospitals: a literature review. BMJ Qual Saf 2011;20:128-33.

4 Institute of Medicine. Hospital-based emergency care: at the breaking point. The National Academies Press, 2007.

5 Solet DJ, Norvell JM, Rutan GH, et al. Lost in translation: challenges and opportunities in physician-to-physician communication during patient handoffs. Acad Med 2005;80:1094-9.

6 Bomba DT, Prakash R. A description of handover processes in an Australian public hospital. Aust Health Rev 2005;29:68-79.

7 Petersen LA, Brennan TA, O'Neil AC, et al. Does housestaff discontinuity of care increase the risk for preventable adverse events? Ann Intern Med 1994;121:866-72.

8 Joint Commission Centre for Transforming Healthcare. Improving transitions of care: Hand-off communications. 2010

9 Johnson JK, Arora VM. Improving clinical handovers: creating local solutions for a global problem. Qual Saf Health Care 2009;18:244-5.

10 Catchpole K, Sellers R, Goldman A, et al. Patient handovers within the hospital: translating knowledge from motor racing to healthcare. Qual Saf Health Care 2010;19:318-22.

11 Pothier D, Monteiro $\mathrm{P}$, Mooktiar M, et al. Pilot study to show the loss of important data in nursing handover. Br J Nurs 2005;14:1090-3.

12 O'Leary KJ, Thompson JA, Landler MP, et al. Patterns of nurse-physician communication and agreement on the plan of care. Qual Saf Health Care 2010;19:195-9.
13 Arora VM, Johnson JK, Meltzer DO, et al. A theoretical framework and competency-based approach to improving handoffs. Qual Saf Health Care 2008;17:11-14.

14 Behara R, Wears RL, Perry SJ, et al. A conceptual framework for studying the safety of transitions in emergency care. In: Henriksen K, Battles JB, Marks ES, et al. eds. Advances in patient safety: from research to implementation. Vol 2. Rockville, MD, 2005.

15 Ye K, Mc DTD, Knott JC, et al. Handover in the emergency department: deficiencies and adverse effects. Emerg Med Australas 2007;19:433-41.

16 Talbot $R$, Bleetman A. Retention of information by emergency department staff at ambulance handover: do standardised approaches work? Emerg Med J 2007;24:539-42.

17 Haig KM, Sutton S, Whittington J. SBAR: a shared mental model for improving communication between clinicians. Jt Comm J Qual Patient Saf 2006;32:167-75.

18 Hilligoss B, Cohen MD. The unappreciated challenges of between-unit handoffs: negotiating and coordinating across boundaries. Ann Emerg Med 2013;61:155-60.

19 Patterson ES, Wears RL. Patient handoffs: standardized and reliable measurement tools remain elusive. Jt Comm J Qual Patient Saf 2010;36:52-61.

20 Apker J, Mallak LA, Applegate EB, et al. Exploring emergency physician-hospitalist handoff interactions: development of the Handoff Communication Assessment. Ann Emerg Med 2010;55:161-70.

21 Hodges BD, Kuper A, Reeves S. Discourse analysis. BMJ 2008;337:a879.

22 Pope C, Mays N. Qualitative research in healthcare, 3rd edn. Oxford: Blackwell Publishing, 2006.

23 Quality care for older people with urgent \& emergency care needs. 2012. http:/ www.bgs.org.uk/campaigns/silverb/silver_book_complete.pdf

24 Banerjee J, Conroy S, Cooke MW. Quality care for older people with urgent and emergency care needs in UK emergency departments. Emerg Med J 2013;30:699_ 700.

25 Cheung DS, Kelly JJ, Beach C, et al. Improving handoffs in the emergency department. Ann Emerg Med 2010;55:171-80. 